\title{
Electronic trading and its implications for financial systems
}

\author{
Helen Allen, John Hawkins and Setsuya Sato ${ }^{1}$
}

\section{Introduction and themes}

The adoption of electronic trading systems has transformed the economic landscape of trading venues and is proving a force for change in market architecture and consequential trading possibilities. ${ }^{2}$ The term "electronic trading" is used in many ways. In this paper, it refers mainly to trading in wholesale financial markets (as opposed to e-commerce more generally - see, for example, Long (2000) for a survey of the latter) and focuses on the central feature of electronic trading systems, automation of trade execution. Such systems usually also feature electronic order routing and dissemination of trade information and may link through to clearing and settlement. Electronic trading both removes geographical restraints and allows continuous multilateral interaction (whereas telephone trading allows only the former and floor trading only the latter). It allows much higher volumes of trades to be handled, and in customised ways that until recently would have been technically impossible or prohibitively expensive. This paper considers areas where these enabling effects have been particularly important in wholesale financial markets and how they raise wider, policy implications.

In this introduction, two of the overarching issues that run through this discussion of electronic trading are highlighted. One is the importance of distinguishing between ultimate and intermediate objectives, for example whether a policy concern over transparency is an end in itself or, as argued here, a "means to an end". Second is the pervasive presence of network-related policy issues, encapsulated in the question of how, or indeed whether, to respond to perceived problems over market fragmentation. This section begins by presenting an analytical framework for the discussion.

\subsection{Analytical framework}

Much traditional economic literature has little to say about the practicalities of price formation, assuming it away as perfect and frictionless or occurring via the fiction of the Walrasian auctioneer. This "black box" has been illuminated in recent decades as microstructure research has analysed how different market structures and imperfections influence trading outcomes. ${ }^{3}$

This field of research has analysed how market architecture - which should be understood to mean broadly the key features of market structure such as participation arrangements, venues and trading protocols - influences trading outcomes of prices and quantities. These decisions about architecture also affect aspects of a market's quality - its performance across attributes such as liquidity, trading costs, price efficiency and resilience to shocks. Ultimately, market quality has broader welfare

Ms Allen is Adviser, Market Infrastructure Division at the Bank of England and Mr Hawkins and Mr Sato are a Senior Economist and Head of Special Meetings respectively at the Bank for International Settlements. The authors particularly wish to thank Simon Buckle, Charles Gaa, Gabriele Galati, Joe Ganley, Giuseppe Grande, Toni Gravelle, Serge Jeanneau, Jamie McAndrews, Inke Nyborg, Sarah Parkinson, David Rule, Clifford Smout, John Trundle, Philip Turner and participants at a SUERF colloquium for helpful comments on this paper. In addition, the authors all benefited from discussions last year while participating in the Electronic Trading Working Group of the G10 Committee on the Global Financial System. The opinions expressed are those of the authors and not necessarily shared by the Bank of England, the Bank for International Settlements or its other member central banks.

2 There is now a range of work concerning aspects of electronic trading, as references throughout this paper attest. There is also a considerable amount of work on the effect of technology on market structures and on electronic finance more generally - eg Bar (2001), Mishkin and Strahan (1999), Claessens et al (2000) and Sato et al (2001).

3 Market microstructure literature studies the processes/outcomes of exchanging assets under explicit trading rules - O'Hara (1995) provides a theoretical review; see also the recent survey by Madhavan (2000b). 
implications - such as through the contribution of the efficiency of the financial system to economic growth and through the performance and resilience of markets to financial stability. ${ }^{4}$

Innovations such as electronic trading can lead to changes in this process. The introduction of new trading technology offers greater possibilities in market architecture, which affects market quality and ultimately influences welfare more widely. Box A (overleaf) characterises how, across the many interacting and overlapping elements of market architecture and quality, the practical choices have widened, enabling trading arrangements to be varied in ways previously infeasible. The flowchart below provides an indicative summary. ${ }^{5}$

\begin{tabular}{|l}
$\begin{array}{l}\text { Innovation } \\
\text { (eg electronic } \\
\text { trading technology) }\end{array} \longrightarrow \begin{array}{l}\text { Market } \\
\text { architecture }\end{array} \longrightarrow \begin{array}{l}\text { Market } \\
\text { quality }\end{array} \longrightarrow \begin{array}{l}\text { Broader } \\
\text { welfare } \\
\text { effects }\end{array}$ \\
\hline
\end{tabular}

Of course, the "optimal choice" of trading arrangements will mean different things to different parties. For example, owners of trading systems might be trying to maximise market share or income. Traders might be aiming to complete deals at the best prices and at low cost, or with minimum delay or maximum discretion - or indeed, any combination of an enormous range of factors which affect trading decisions. Similarly, there are multiple public policy objectives; for example regulators focus particularly on the integrity of markets and consumer protection while central banks concentrate on systemic financial stability implications.

No single arrangement is preferred by all players and what benefits one set of participants can be disadvantageous to others. The microstructure area is replete with trade-offs, gainers and losers. The multiple objectives at every stage make it unsurprising that there is no unanimity on what constitutes "optimal" trading arrangements, including at the level of public policy. There is no single, widely agreed "social welfare" measure to optimise.

\subsection{Ends and means - intermediate and ultimate objectives}

Which perspective is adopted clearly affects the terms of the debate. The discussion in this paper is directed towards the right-hand side of the diagram, essentially overall market, financial stability and public interest issues. In this context, it could well be that focusing only on the form of some specific elements towards the left-hand side - be it the details of technology or the specifics of market architecture - could result in a suboptimal outcome from the broader perspective of market quality and social welfare. Indeed, aspects such as market architecture might more usefully be considered as intermediate objectives rather than as public policy aims in themselves.

This perspective applies particularly to transparency of information about the trading process (timely information on the prices and quantities of potential and executed orders). The form of disclosure trading systems should adopt is a highly contentious issue. There is debate about how far regulators should, or indeed can, impose transparency rules. Findings about the precise effects of such rules are inconclusive. It is agreed that transparency of trading information is a very important factor in helping markets function effectively, especially for retail interests. However, there is also evidence that after a certain point in certain market segments, insistence on more transparency can be unhelpful and even damaging to market quality (as explained in Section 3.3). This area, long debated amongst market practitioners, is now recognised in policy discussions.

4 Financial systems are integral to the funding of capital accumulation, one of the fundamental drivers of economic growth. Greater efficiency in infrastructure mechanisms such as trading systems can reduce frictions in financial systems, helping to bring savers and investors together more efficiently, thus aiding growth. Links between the functioning of financial systems and growth are explored in Levine (1997) and more recently, for example, in Leahy et al (2001) with empirical analysis.

5 The last three out of the four stages characterised are similar to that of the traditional "structure/conduct/performance" framework from industrial organisation literature - see, for example, the textbook by Carlton and Perloff (1999). The process indicated in the flowchart and Box A may well be iterative, as welfare improvements stimulate further innovation, and so on. 


\section{Box A - A framework for illustrating the effects of electronic trading}

This box shows how innovation in markets - here the introduction of electronic trading - can open up a greater range of possibilities in the trading process, which in turn can affect overall market performance and broader welfare.

Markets can be described in terms of a number of key features which combine to determine the form of the trading that occurs. These aspects of market architecture include which participants have access to the trading platform, the degree of transparency in the trading process, and the trading protocols such as order types and opening hours. Related to these are aspects of broadly defined market quality, such as trading costs and liquidity. In the diagram they are represented as a circle rather than on two axes as they closely interact and overlap with one another. ${ }^{*}$ They all combine to feed through to "ultimate objectives", ie the effect on broader welfare.

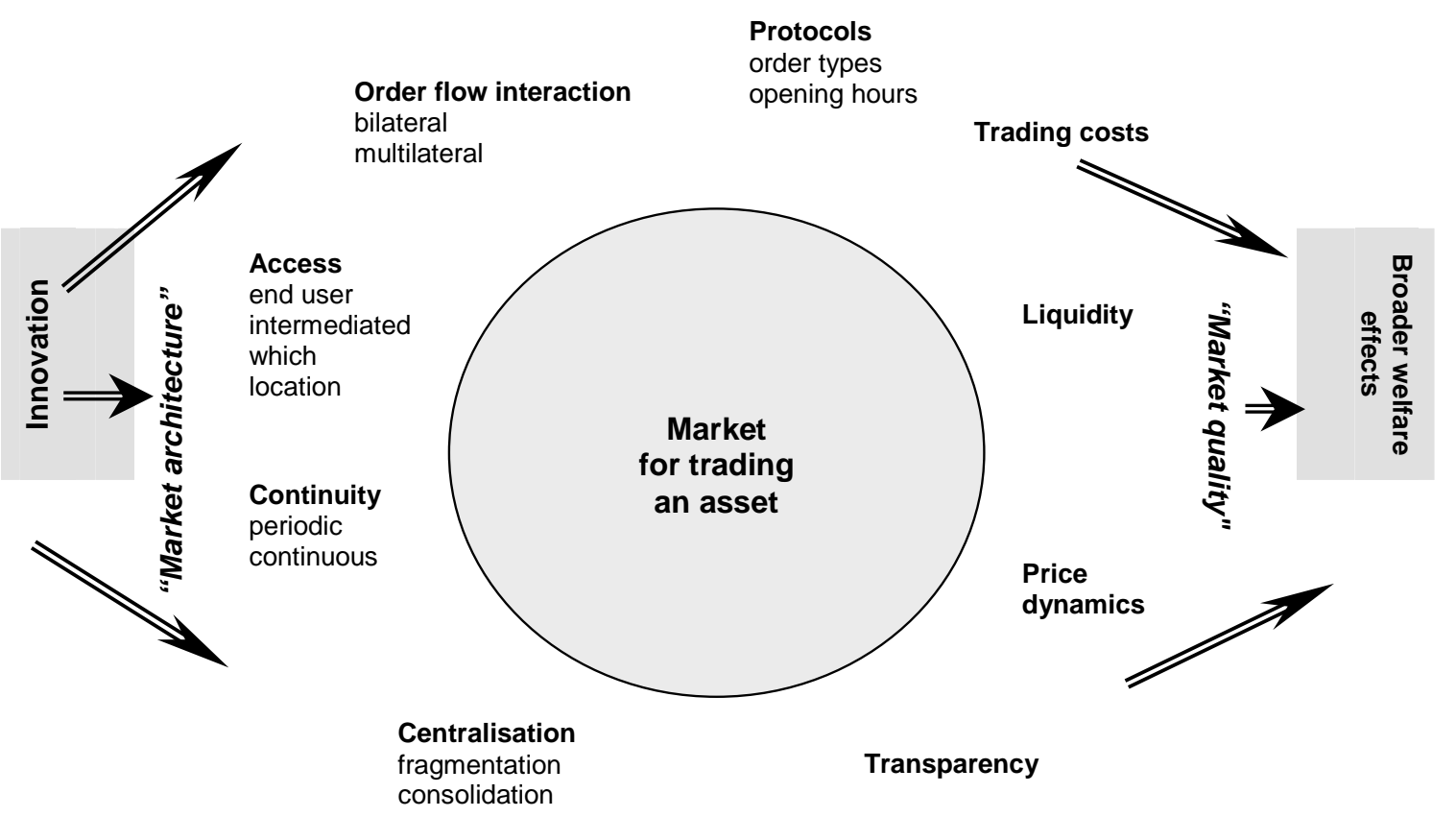

In terms of the diagram, any key feature of the market (examples of which are in bold type around the circumference) may in principle take several, possibly many, forms. For example, access can be for end users or intermediated, geographically limited or unlimited - a theoretical list of possibilities would be very long (other indicative examples are placed underneath some of the key features.)

In practice, the trading arrangement for any specific asset in its market segment could be defined by highlighting the relevant items on the lists of key features. For example, in the OTC fixed income markets, access is intermediated by dealers. Transparency is limited. And, so long as this market is telephone-based, there is probably little alternative to these arrangements.

However, the innovation of electronic trading can bring an array of other possibilities within practical reach. In the fixed income example above, order books can become feasible, allowing customers direct access as well as through dealers. Electronic systems can readily disseminate trading information, creating potentially higher transparency.

The result is that electronic trading opens up a far wider range (and combination) of possibilities in the trading process than were hitherto available. This of course begs questions such as "what to choose? - which combination is best? - what are the wider implications?" - issues which are raised in this paper.

* Naturally, any classification of such features is to some degree arbitrary and the above is intended as a presentational device. There are numerous elements that contribute to the overall trading process. 
Regulatory and policy instincts typically - and probably rightly - generally favour more transparency. In many areas of public policy greater openness is widely recognised as beneficial to processes, expectations and outcomes - disclosure practices in accounting and the transparency of the monetary policy process are two important such cases. However, and possibly counter-intuitively, the reverse can be the case in some contexts of trading, where "too much" transparency can, for example, reduce market liquidity.

In terms of the simple framework above, a policy which makes greater transparency an objective in itself risks ignoring potential negative effects on market quality - and hence on broader investor welfare and the effectiveness of the financial system. Indeed, were transparency to be "maximised" as a policy end in itself, that aim could prove precisely at odds with the wider objectives to which policy is typically addressed.

\subsection{The pervasiveness of networks and challenges for policy}

Network issues permeate analysis of trading. They vary from the network externalities of markets attracting liquidity to practical consideration of physical network access arrangements. The greater use of electronic systems and linkages for trading highlights these effects.

Although network technologies may broaden access and in principle enable "more perfect" markets, the immediate reality may prove less benign. For example, the presence of electronic networks can embed existing privileges, with network access and design choices giving strategic advantages to certain classes of participants (see Section 5). And the effects recognised in network economics (see Box B) are a powerful influence in this area. They can lead to sustained suboptimal equilibria in market arrangements and a tendency to consolidation. While the latter may bring about significant scale efficiencies in market processes, if (near) monopoly power emerges there can be undesirable outcomes such as lack of choice and monopoly pricing.

The prospect of such outcomes creates difficult policy questions. First, identifying a suboptimal situation is not easy given the different, possibly conflicting, objectives of affected parties. Then, even where problems are recognised, they may represent a temporary phase of an immature market, which competitive forces and innovation could well resolve. Intervention may be judged inadvisable unless there is demonstrably a sustained problem plus a response which could clearly improve on the market outcome.

Analysis of such situations carries clear dangers of misinterpretation. The multiple, potentially competing, public policy objectives make it likely that not all can be simultaneously achieved. There are dilemmas between intervention or "wait and see". The former could risk stifling competition and limiting innovation in fast changing environments, while the latter might risk missing opportunities to prevent problems becoming widespread.

Responses to market fragmentation illustrate the difficulties, seen especially in equity markets when alternative trading venues become available. Concerns are associated with whether the liquidity of the "main" market is reduced - which could mean less market depth to absorb large trades and shocks, reduced price efficiency, higher search costs and price comparison being made more difficult. However, the flip side is that the additional execution routes may reflect greater variety of services, competition to cut costs and innovation in trading systems.

This raises significant questions about the efficacy of policy intervention. It is illustrative of the dilemmas that views can differ starkly even over whether there is a problem to be addressed. If the situation is believed detrimental to public policy interests, there are judgments to be made over whether market forces will resolve difficulties (say, through consolidation following competitive attrition of illiquid venues and/or technological innovations offering linkages). Or whether, and in what manner, to intervene actively.

\subsection{Outline of the rest of the paper}

The development of electronic trading in wholesale financial markets is considered in Section 2 where it is observed that the widely differing forms and speeds of penetration can largely be explained by the characteristics of the asset traded and its market segment along with specific factors such as regulation and competitive conditions. 
Sections 3 and 4 consider changes to particular aspects of markets' architecture and quality closely associated with the use of electronic trading. In the former, changes brought about in the areas of access, transparency and consolidation/fragmentation are highlighted. The latter section discusses impacts on costs, liquidity and price dynamics, drawing particularly on recent evidence. The lessening influence of physical restrictions on all these areas has brought into stark focus questions of what are appropriate choices, the implications of which are appearing on policy agendas worldwide.

The final section highlights some of these policy issues, emphasising the perspective of the overall quality of markets and broader welfare. Particular consideration is given to financial system stability issues along with the oversight-related concerns associated with the range and speed of changes in trading technology. As brought out above, it is also notable how network effects in some way influence all of these - from the practical details of system design, to the problems and solutions of oversight, competition and access to network infrastructure, as well as the economics of networks which pervade the whole subject.

\section{Contrasting development of electronic trading}

Looking across financial markets, it is clear that electronic trading has penetrated different sectors very unevenly. This varied pattern of development between types of assets (and market segments within each) can, however, typically be explained by the interaction of a number of factors.

Existing market structures, regulatory and competitive factors and the varied needs of traders have all affected the integration of new technology into mainstream trading. And an important element is the asset type, since standardised, homogenous products have proved "easiest" to migrate to electronic trading. In terms of the schema in Box A, there are clear differences in what possibilities are feasible, both between assets and within different segments of any particular asset market.

The following reviews developments in the equity, fixed income and foreign exchange markets, ${ }^{6}$ which between them illustrate the varied development path of electronic trading and its wider effects on markets (the latter being explored in Section 3). Moreover, electronic trading is presumably at only an early stage of development - the future may see, for example, distinctions between market sectors blurring as systems develop for portfolio trading of multiple assets; and advances in networks perhaps with internet use more widely integrated. Similarly, the direction of developments to date inevitably reflects the current technology - advances will widen the choices available in nextgeneration trading systems, potentially enabling further waves of change to market arrangements.

\subsection{Equity markets: United States versus Europe}

Equity markets are the best known, most widely studied examples of electronic trading. The contrasting development patterns in the United States and Europe show how electronic trading can penetrate the market for the same assets in a very different manner. Whereas the US equity market has been characterised by a proliferation of alternative electronic trading venues alongside relatively few traditional exchanges, Europe has been more notable for the absence of separate systems, with electronic trading instead incorporated within its many traditional exchanges. In both markets the common features of the liquidity and relative homogeneity of the major equity issues has made it relatively straightforward and cost-effective to introduce electronic trading.

\subsubsection{US equity markets}

The so-called "traditional" markets (floor or telephone, albeit with high levels of automation) in the United States are dominated by the three national markets, of which the New York Stock Exchange

6 While these particular examples have been chosen to illustrate patterns of developments, to a lesser or greater extent all financial markets have been influenced by electronic trading developments. For example, Tsang (1999) reviews automation in futures trading, where electronic trading has been well established for some time. Banks (2001, Chapter 4) describes electronic trading in a range of markets, with particular focus on the role of the internet. 
and the smaller AMEX are basically order-driven and floor-based. Nasdaq, the second largest venue, is telephone/screen-based (no floor) and has developed essentially as a dealer market with orderdriven facilities becoming available more recently.

Separate electronic trading systems have gained a foothold in the United States over recent decades, but it is within the last five years that alternative venues have proliferated. A particular trigger in the US case was regulatory and mainly limited to Nasdaq - the appearance of several ECNs (Electronic Communication Networks) can be directly associated with regulatory changes affecting the display of orders. ${ }^{7}$ All these ECNs offer a model based on an electronic order book (which was unavailable in the main markets), though within that they compete on differences in market architecture. Moreover, the United States has significant retail participation in equity markets, business in which a number of ECNs specialise. These country-specific factors illustrate why results from studies of one market may not necessarily generalise to others, a pertinent point given the dominance of studies of the NYSE and Nasdaq in the literature.

\subsubsection{European equity markets}

In contrast to the United States, most electronic trading facilities in Europe have developed within existing exchanges. Over a period of some years, continuous electronic order books have been incorporated within mainstream exchanges, offering trading methods that in the United States were only available by routing away from the traditional venues.

This has been able to occur in an environment generally less influenced by regulation than equivalent US markets, making European exchanges more open to competitive pressures. Demutualisation by many major exchanges additionally gives clearer commercial incentives for innovations and efficiencies. Cross-border competition has led to numerous mergers and alliances among European exchanges, particularly in the last five years. Investment behaviour and trading platforms are moving from being wholly split on national lines to a greater pan-European, sectoral emphasis ${ }^{8}$, particularly with the launch of the euro. It is uncontroversial to predict a further reduction in the number of separate European exchanges, ${ }^{9}$ although currently there are several new contenders targeting different segments of the cross-border European market, notably in the market for larger stocks. This juxtaposition of consolidation with proliferation is explored in Section 3.1.

These developments result in a vastly reduced opportunity, compared to the United States, for separate off-exchange trading systems (especially if designed as an electronic order book) to enter the market - such entrants would presumably have to offer some particular advantage that cannot be obtained on the exchange systems. Bearing this out, there are relatively few separate electronic trading venues operating in European markets.

\section{$2.2 \quad$ Fixed income markets}

Moves to electronic trading in fixed income markets have been slower than for equities. For many years, bonds of all types were typically traded in telephone dealer markets, ${ }^{10}$ into which electronic systems have made (limited) inroads only very recently. Fixed income systems have recently proliferated in number - an annual survey by the Bond Market Association (2000) identified some 70 systems in 2000, up from only 11 three years earlier, although few have significant volumes. Most market commentators, such as Brown (2001), expect consolidation in the number of platforms.

7 The regulatory trigger was the SEC's order-handling rules, implemented in January 1997. McAndrews and Stefanadis (2000) set out the regulatory and technological developments that have affected the ECNs. Separately, there are a range of other electronic trading systems available which offer a considerable variety of market architecture. For a further discussion of the US experience, see Davis and Steil (2001, Chapter 8) and Domowitz and Steil (2001b).

8 See, for example, Cavaglia et al (2000).

9 See, for example, The Economist (2001a, 2001b). A list of automated exchange mergers and alliances over 1997-2000 is presented in Davis and Steil (2001, table 7.2). See also the discussion of stock exchange alliances in Gaa et al (2001, p 54).

10 In a typical telephone dealer market (eg that for UK government securities), customers telephone orders to dealers who either are obliged to quote prices or do so on a "best efforts" basis. The dealers manage their inventory in an inter-dealer market, sometimes intermediated by inter-dealer brokers and sometimes dealing directly with other dealers. 
The variety of automated trading system types already introduced is notable (a variety previously more characteristic of equity markets), given the uniformity of traditional bond market arrangements. There are now order-driven markets in addition to several automated versions of dealer markets, offering a range of participation and access arrangements for dealer, inter-dealer and customer sectors (for a taxonomy, see BMA (2000)).

The later arrival of electronic trading in fixed income markets compared to equities reflects distinct differences between the two. Fixed income products are far less homogenous, with many more separate and individually less liquid issues than equities, making it technically more difficult and more expensive to introduce automated systems. The Economist (2000) suggests there are over 4 million fixed income securities on issue in the United States (varying in coupon, maturity, frequency of interest payments, etc) compared with a few thousand listed shares. Trading style differs - relative to equity markets there tend to be fewer but larger trades, ${ }^{11}$ with many participants holding issues to maturity. Moreover, while it seems likely that the trading of equities on centralised exchanges encouraged early transitions to automation, the opposite position delayed bonds from making the move.

Within the fixed income sector, electronic trading has made most inroads into certain government bond markets. It is estimated that in $200040 \%$ of US Treasury securities transactions were done electronically, nearly double the volume a year earlier (Moszkowski et al (2001)). Similarly, in Italy about half the trades in government debt are now conducted on the MTS system developed with the cooperation of Italian public authorities. ${ }^{12}$ Electronic trading in corporate bond markets remains much lower (only $10 \%$ of US corporate bond volumes in 2000 according to Moszkowski et al) as they are far more heterogenous. A common pattern has been for platforms to begin trading government bonds, later expanding into other, more heterogeneous, fixed income issues. Though this reflects the greater amenability of the relatively more standard and liquid government securities to current electronic trading platforms, this distinction may reduce as electronic systems develop to accommodate trading of less liquid issues - see the discussion in Section 4.3.1. ${ }^{13}$

\section{$2.3 \quad$ Foreign exchange markets}

Electronic trading has had an important presence in the inter-dealer spot foreign exchange market for over a decade; the BIS triennial survey shows that $20-30 \%$ of interbank trading in the major currencies was conducted electronically in 1995 and this rose to about 50\% in 1998 and was estimated at over $90 \%$ by 2001 . For some years there have been two major systems (EBS and Reuters) which now tend each to specialise in particular major currency pairs. The development of these systems is described in Chaboud and Weinberg (2002). Both systems have been designed as order books, in which dealers can see the best bid and offer in the market, alongside the best bid and offer that they could trade subject to their institutional credit limit structure.

These electronic systems are now used for the majority of spot inter-dealer trading in major currency pairs. Consequently, the inter-dealer segment of the market has mostly (but not entirely) moved away from voice broking, and the electronic systems now act as a standard reference for pricing. While the structure of the foreign exchange market before the introduction of electronic trading was (rather akin to fixed income) a fragmented bilateral telephone market, the rapid adoption of systems in the interdealer sphere reflects the liquid, homogenous nature of the product that can be traded in standardised units. The latter points presumably explain the earlier presence of electronic trading in foreign exchange compared to fixed income markets.

11 The comparison of the UK equity and gilt markets found in Annex A of DMO (2000) suggests that the average gilt market trade was approximately 30 times that in the equity market. Differences between the characteristics of government bond and equity markets are detailed in Gravelle (2001).

12 Claessens et al (2001) give examples of platforms for trading in bonds from a number of emerging economies, including Asian bonds, Latin American bonds and Brady bonds. Bank of Japan (2001) notes that since mid-2000 a number of bond trading systems have been established in Japan, but trading volumes are still low.

13 Fixed income markets are much less studied than are equity markets: Goodhart and O'Hara (1997) noted that "the absence of much market microstructure analysis in (government) bond markets is particularly surprising", a comment echoed by Lyons (1998) and Gravelle (2001). One recent study is Study Group on Fixed Income Markets (2001). 
While electronic trading has come to dominate the inter-dealer market, systems have made far less impact on the business of large corporate customers. However, this may be on the point of changing as several internet-based systems aimed at this area are now being rolled out. These systems promise more flexibility (eg. tailored quantities and currency pairs available) and utilise the internet's ability to connect disparate and distant parties at low cost. The largest are two multibank systems ( $F$ Xall and Atriax, which began operating in mid-2001) automating the process of customers obtaining a range of executable quotes from member banks. Already other systems are moving to offer links to these.

\section{Effects of electronic trading on market architecture}

This section considers effects on market architecture with which electronic trading is closely associated - focusing on consolidation/fragmentation of markets, decisions about the type of participants' market access and the form of transparency in the trading process. Substantial changes are taking place in these areas in the wake of electronic trading lessening many previous physical rigidities. And as illustrated above, these developments in market structures are closely related to the characteristics of each market / asset type.

\subsection{Fragmentation and consolidation}

Electronic trading is now closely associated with many of the important pressures affecting ebbs and flows in the number of trading venues. ${ }^{14}$ On the one hand, it can stimulate a proliferation of venues, by making markets more contestable as a result of them being cheaper to enter and enabling greater variety of products and specialisation of trading services. On the other hand, electronic systems can enable linkages to bring together sources of liquidity and to harness efficiencies that contribute to consolidation. And affecting all these, the speed of development of the facilitating information network technology has led to a more rapid pace of change.

These effects are of course a feature of any dynamic market, where opportunities for new entrants result in a tendency to fragmentation, typically followed by some reversal when not all attract sufficient business to operate on a profitable scale. ${ }^{15}$ The powerful influence of network effects in this area (see Box B) means that a proliferation of similar trading systems which individually attract little liquidity would be expected to be a transitory phenomenon. Those which become established will need both to add some value and - crucially - to attract, retain or link to a sufficient amount of liquidity.

While these effects imply a tendency to consolidation over time, in any particular market the extent to which electronic trading is currently motivating a phase of fragmentation or consolidation is very dependent on existing structures. In the previously OTC fixed income market, new trading systems are starting to bring together larger groups of users, consolidating sections of the market which formerly relied on bilateral communication. Similarly, users of the main foreign exchange systems now transact through a centralised market, in contrast to fragmented telephone arrangements. By contrast, in equity markets, which were typically dominated by centralised exchanges, the very presence of distinct alternative trading venues (along with large banks and brokers increasingly able to internalise their order flow by offsetting one transaction against another) can increase fragmentation. Yet in some cases the overall balance may be hard to call - consolidation and fragmentation effects can operate in parallel. For example, European equity markets have also seen numerous recent efforts at mergers, alliances and linkages of various kinds.

14 Across the whole trade processing infrastructure, there are wider consolidation issues. Notably, there is considerable scope for consolidation in clearing and settlement procedures, progress on which may be related to exchange consolidation - see eg Gaa et al (2001).

15 Current pressures affecting consolidation in the financial sector as a whole, including its patterns, causes and policy implications, are examined in the report by the Group of Ten (2001), and in emerging economies by Hawkins and Mihaljek (2001). The effect of technology and the internet on fragmentation and consolidation in US equity markets is explored in Madhavan (2000a). 


\section{Box B - network economics effects*}

Network economics effects feature strongly in trading systems and help explain commonly observed features of markets - such as consolidation of market liquidity, the advantages experienced by incumbent trading systems, and tipping effects when a market shifts from one centre to another. The underlying economics of these features occur in a number of industries which are structured around a network arrangement - railways and telecommunications are examples.

In these markets, positive network externalities arise because the value of the network to each participant rises as other participants join. Telephones are a traditional example - in the early days of telephony it was relatively unattractive to join the network since there were few other participants to whom to make calls. However, as the number of subscribers increased, the opportunities for making and receiving calls also increased, enhancing the usefulness and value of the network for all participants, making all users better off.

These positive network externalities similarly apply to market liquidity. All other things being equal, it is better to participate in a bigger than a smaller trading network, since each trader brings additional trading opportunities/liquidity. Positive feedback comes about as a liquid market attracts more participants, all participants benefit from the additional liquidity, making the network more attractive to others, and so on.

In the absence of rigidities or other barriers, the presence of these network externalities in a market would imply a tendency to consolidation. In the trading context, this would work to bring isolated pools of liquidity together.

However, such consolidation may not occur around an "optimal" system. One reason is first mover advantage. An incumbent system may have gained a critical mass of users simply because it was the earliest available. Systems that come to the market later may face formidable hurdles to attract a viable level of participation, even if they offer a better product. Potential users need to believe the costs of switching to the new systems are worthwhile. Moreover, they must expect enough other users will also switch to make the new system an effective, liquid trading venue.

These hurdles may mean users feel "locked in" to a dominant system, in which case a suboptimal equilibrium can be sustained. This position can arise whether a system has become dominant through first mover advantage or through consolidation. In the latter case, even if the consolidation occurred around an efficient, technically advanced system, if it comes to be a (near) monopoly the incentives to maintain those advantages can be eroded. The well known problems of monopoly pricing, technical inefficiencies and abuse of dominant market position may arise.

However, it is by no means inevitable that dominant market positions will be sustained. If an alternative system manages to attract users, it too can enter a virtuous circle of positive feedback. Once a critical level of participation is achieved, the market can tip away from the incumbent and towards the alternative. This switch can be abrupt.

* The information in this box is drawn from: Shapiro and Varian (1999. Chapter 7), which explains the impact of positive network externalities on industries; Domowitz and Steil (2001a), who analyse how network externalities apply to securities trading; and Economides' $(1996,2001)$ papers on network economics and finance.

This ambiguity affecting judgments on the degree of fragmentation/consolidation in any market's trading is added to by fragmentation taking many forms. As discussed in Lee (1998), there is no single dimension by which to evaluate fragmentation. To illustrate, even though the number of separate exchanges (or similar marketplaces) may fall, the range of systems through which orders can be placed may grow if venues offer a wide choice of order routing. For example, an exchange may offer a main market, an upstairs arrangement for block trades and onward routing to associated markets. Alternatively, if there are linkages giving traders seamless access to a range of markets, it may matter little how many underlying venues exist. These effects, making judgments about fragmentation/consolidation far from straightforward, are amplified as the range of technological possibilities increases.

Moreover, and in an innovative market, the degree of concern about fragmentation may alter quickly. Even in the relatively short history of electronic trading, there are cases of fragmentation effects being overridden by technology. For example, systems can now offer "virtual consolidation" on a single 
screen to combine information from stocks traded at multiple venues. Or solutions may take the form of "smart search agents", automated devices to seek out disparate sources of liquidity (see Section 4.3.1).

From the perspective of market users and policymakers, the important questions are whether the available routes can bring together liquidity in an appropriate manner to meet trading needs and enhance market quality. For example, whether there is sufficient order interaction to allow effective price formation and depth of liquidity, to the benefit of the ultimate end users. Ways in which electronic trading is influencing these matters are discussed in Section 4. However, as brought out in the introduction to this paper and discussed further in Section 5, it can be difficult even to gain consensus on whether there is a problem of fragmentation, and still more difficult to judge whether a policy response is appropriate, and if so what should be the response.

\subsection{Market access}

\subsubsection{Forms of access}

Electronic trading can widen access to trading systems across several dimensions. Physical limitations that once rationed access to traditional venues no longer bite, meaning additional users can now participate at minimal marginal cost, removing the economic need to limit access through membership restrictions. At the same time remote linkages remove geographic limitations on the pool of potential users, and continuous multilateral interaction is enabled. From the system providers' viewpoint, the opportunities to enter the market are also greater than hitherto in the light of the fall in costs and enabling technology. And from the perspective of the issuer of securities, there can be opportunity to access a wider pool of potential investors. ${ }^{16}$

This turnaround in the economics of access means that in principle arrangements can be decided more in response to the needs of the market. For example, whether there is a role for intermediaries and whether it is appropriate for different customer types (eg retail/wholesale or by different institutional status) to participate in the market can become more a matter of choice rather than being effectively dictated by external constraints. Changes in these areas can affect the whole design of a market.

This is not to say that limitations on access to markets no longer exist - in practice they still have strong effects, albeit with different forms proving more important. Notably, the legal/regulatory factors associated with cross-border transactions now appear to be the more relevant geographic constraint.

Additionally, there may be differential access to telecommunications infrastructure networks - termed "access asymmetries" by Bar (2001). For example, dedicated private lines or the use of the internet influence which classes of participant can have physical access to systems. ${ }^{17}$ Suboptimal outcomes could arise, for example if intermediaries own new trading platforms that in other respects would disintermediate them - their incentive may be to ensure the network design retains their privileged access positions. Implications of the risks of anticompetitive biases in networks are discussed in Section 5.2.

\subsubsection{Access and intermediation}

The greater access possibilities offered by electronic trading have perhaps most obviously brought into question the role of intermediaries. There has been some shift away from pure dealer structures towards continuous auction arrangements where users can transact directly with one another. This has especially occurred in large, liquid markets (notably major equity and foreign exchange) where

16 Longer opening hours may also seem to be cheaper and more feasible - but in practice longer (even 24-hour) trading sessions do not seem valued in wholesale markets. Reasons may include a preference for a distinct end-of-day closing for risk management procedures and, more fundamentally, lack of demand from customers and the problems of thin markets.

17 Moreover, moving to different or additional systems is far from friction-free. For example, at the most practical level it may involve extra screens, linkages and staff training. While it is likely that such costs will progressively lessen, the point at which they can be virtually ignored seems distant. 
end investors are likely to be able directly to match their requirements over a reasonable period of time. This wider access to trading systems increases competitive pressures on dealers and typically forces those which remain to focus more on value added services such as corporate finance, advisory services and risk management. However, in OTC markets, where a larger portion of trades are characterised by asynchronous supply and demand in less liquid securities, the matching services of a dealer have a clearer role and this is reflected in many electronic trading systems in such markets incorporating dealer structures, as illustrated in Section 2.

However, despite the developments (such as customer access to order books) that might have been expected to marginalise much of their role, dealer intermediation remains. Reviewing literature pertinent to this issue, Madhavan (2000b) highlights some features, such as the significant costs a direct limit order trader might face in order to monitor changing market conditions, that could explain their continued importance. Supporting this, anecdotal evidence collected by CGFS (2001a) from customers in foreign exchange and fixed income markets pointed to some valuing the personalised research, advice and execution offered by dealers. Moreover, in practice, systems are some distance from being able to seek out all sources of liquidity automatically, and disparate sources of liquidity (eg due to upstairs arrangements) make this search a valued service of intermediaries.

\subsection{Transparency}

\subsubsection{The uneven effects of changes in transparency}

One of the commonly cited benefits of electronic trading is that it can facilitate greater pre- and posttrade transparency. ${ }^{18}$ While this is undoubtedly true, there are significant questions, both theoretical and practical, about the extent to which implementing greater transparency across all market segments benefits the quality of a market. Underlying the issue is that transparency arrangements affect the balance of information among participants. Evidence from a range of studies (see Madhavan (2000b)) demonstrates that this influences the degree of information in the order flow, price discovery and liquidity. ${ }^{19}$

Changes to transparency rules tend to benefit one group of participants and their objectives at the expense of another, creating winners and losers. While in many respects the literature on the effects of transparency is inconclusive (see, for example, Ganley et al (1998)), the presence of these tradeoffs is very evident. This highlights the importance - stressed in the introduction to this paper - of the perspective of the debate. From the public policy viewpoint, recognition that transparency arrangements can have uneven influence on "ultimate" objectives such as market quality and broader welfare is clearly crucial. Even though understanding of this area is very incomplete, the evidence that there is not a simple, unidirectional relationship between transparency and quality of markets deserves considerable weight in policymaking.

Some flavour of why greater disclosure may not necessarily benefit the overall market is given in the following stylised examples. An illustration of a tension between post-trade transparency and liquidity occurs in a multiple dealer setting such as in many government bond markets. Faced with an unpredictable flow of large customer orders, dealers who maintain a continuous presence in the market seek to manage the risks arising from sharp variations in their inventory of securities by inter-

18 This section focuses on transparency in terms of the ability of market participants to observe information about the trading process. As discussed in O'Hara (1995), there are multiple dimensions to transparency. Consideration of it can be split into pre-trade information on order sizes and quotes, and post-trade information on prices and quantities of executed trades. Other considerations include the timeliness of the information made available, which (subset of) participants can observe certain aspects, and pre- and post-trade anonymity (whether identities are revealed).

19 Madhavan (2000b) surveys results regarding transparency from theoretical, empirical and experimental literature. Much of the work uses underlying models based on asymmetric information - these consist of two classes of market participants, informed traders with private information on future asset values and uninformed (liquidity motivated) traders, and explore how these groups trade under different conditions. Such models are mostly applicable to equity markets in which private information on assets plays an important role. There is also a range of models based around inventory adjustment, consisting of dealers who attempt to restore their inventories to some desired level by adjusting their quotes and trading behaviour. As discussed in Gravelle (2001), these also fit closer with the structures typically seen in fixed income and foreign exchange markets. 
dealer trading to rebalance their holdings. Were stricter post-trade transparency imposed in terms of requiring more rapid publication of large transactions, it would reduce dealers' opportunity to conduct this inventory adjustment. This could increase their risk management costs - which may be passed onto customers - and could lead to a less efficient allocation of risks in the market. Both liquidity and price discovery could be impeded. (Gravelle (2001) provides more details on the above arguments.)

Equivalent tensions with pre-trade transparency requirements can arise where transactions contain (and are motivated by) private information reflecting legitimate investor research/beliefs or portfolio strategy. Were disclosure imposed which revealed "too much" about intended trades, it could effectively expropriate that private information for the public trading venue. The predictable result of such rules would be that traders would act to minimise the cost of the loss, for example by splitting the trade to reduce the observable information content or by switching venues to avoid the regime. Or they might exit the market entirely.

\subsubsection{Transparency - potential and practice with electronic trading}

Electronic trading creates the potential for a very high degree of transparency across the whole trading process. In principle, systems can disseminate real-time pre- and post-trade information market-wide. Conversely, they can operate with minimal information leakage, in a manner that trading based on personal contact could not achieve. As electronic systems become more sophisticated, they make it more feasible to move along the multidimensional spectrum of transparency. They can more readily meet different users' preferences regarding information, some of which were once too complex to put into practice.

For example, the basic demand for anonymous trading is now met through many electronic systems. Some of the systems becoming available are specifically designed to eliminate (pre-trade) information leakage, enabling users to specify precise orders without giving away potentially valuable information to competitors. ${ }^{20}$ Other systems offer choices such as "iceberg" orders that are automatically matched if hit but are not visible on an order book. In contrast, the upsurge of electronic order books in equity markets has often led to the arrangements being more transparent than the structures they replaced. Presumably the practical possibilities will grow as the technology develops further. ${ }^{21}$

In itself, this existing variation in transparency arrangements suggests that the form and degree of disclosure vary with largely market-specific factors. Considerations include the perceived role of the information in attracting liquidity to the system, the needs of its range of users and style of trades (eg retail/wholesale, whether market-moving) and the commercial value of the data. And importantly, different classes of trading systems lend themselves to different forms of transparency: the style of information concerning a call market differs from that readily available from an order book or a dealer arrangement. Regulatory requirements may or may not constrain the actual outcome, given that there are strong reasons why systems typically would choose to make available some degree of trade information (eg to attract liquidity and/or for commercial data promulgation).

\subsubsection{Some likely effects of electronic trading on transparency}

Segregation of trading arrangements largely according to transparency regime has long been a feature of markets. Notably, virtually all exchanges have particular arrangements for block trades ("upstairs trading"), with lower transparency requirements, often in the form of delayed publication. The integration of electronic trading hugely increases possibilities for different arrangements, in principle

20 Such systems are a response to the above point, that in a transparent environment, wholesale traders may well disguise these orders in some way to avoid giving away information on their strategy which may lead to the market moving against them. The pre-trade opaque class of systems in contrast actually allow traders to input their true order preferences to the system with complete accuracy since the information is only "seen" by the computer system. These systems aim to meet a demand for trading without losing informational advantage.

21 Considering transparency more widely, other forms of information dissemination also become more feasible as technology is integrated. For example, information on the characteristics of numerous securities can be made available (as seen in the systems implemented in several government bond markets) while transparency of processes, such as order routing information, can also be offered. However, questions have been raised (see D'Avolio et al (2001) and Ferguson (2001)) about the extent to which the increased quantity of information enabled by technology is accompanied by an increase in its quality. 
virtually anywhere on a spectrum, between complete transparency and complete opacity. An outcome may well be an even greater variety in transparency levels across (and within) different trading venues than seen hitherto.

Moreover, if electronic trading enables the implementation of systems which give "appropriate" incentives in trading behaviour (such as to input "truthful" orders, as explained in footnote 20), one result could be greater efficiency of price formation. As set out in the introduction, this argues for seeing transparency as a means to an end for aiding market quality, rather than as an end in itself.

The current regulatory focus on transparency in securities markets largely reflects concerns that greater choice of trading venues/routings raises about level playing fields and fairness of information across the whole market. For the context of the immediate discussion, there are clear risks that a response involving an attempt to impose common transparency standards could be counterproductive if it overlooks the wider repercussions of disclosure rules and creates distortions by neglecting differences between/within markets. These questions are particularly important across wholesale, professional markets. For retail (ie non-market-moving and non-information-carrying trades - albeit not the focus of this paper), the concerns are very different, relating more to consumer protection and informed consumer choice, where the benefits of greater transparency seem less ambiguous.

\section{Effects of electronic trading on market quality}

Closely related to market architecture are aspects of market performance. This section looks at influences of electronic trading on transactions costs, price dynamics and liquidity, all of which contribute to the overall quality of markets.

\subsection{Trading costs}

At the outset of this paper, the performance of financial systems was recognised as having broader welfare effects. Trading costs are one of the more direct indicators of this performance. For example, in a recent study of the wider implications of trading costs, their reduction was shown to be associated with a lower cost of equity capital, which has macroeconomic significance - see Domowitz and Steil (2001b).

Benefits such as these could be assuming more importance since electronic trading and associated computing advances have given new impetus to trading cost reduction across all fronts. There is now scope to reduce what was once a "set cost" of business - one reason for the greater focus by institutions on analysing and cutting trading costs. These costs for end users can be divided into explicit costs (eg physical overheads, fees, commissions, taxes, costs of clearing and settlement) and two main types of implicit costs - bid-ask spreads and market impact costs. Electronic trading is offering routes to reduce all of these. ${ }^{22}$

Looking initially at total trading costs, empirical studies find these are lower for institutional investors on automated than traditional markets, even after controlling for the different mix of shares traded in the two types of market. For example, Domowitz and Steil (2001b) suggest total cost savings in the United States of around 30\% from using automated systems. As for implicit costs, a study of over half a million institutional equity trades by Domowitz et al (2000) suggests they have been falling over time and that they tend to be lower in markets where automated trading dominates.

\subsubsection{Explicit costs}

Electronic systems involve lower set up costs than trading floors, especially when an existing system can be adapted for a new product. More significantly, by replacing labour-intensive processes, they 22 Trading cost studies typically measure costs conditional on execution. There are also costs arising from non-execution,
which particularly affect the placement of limit orders. There are also opportunity costs associated with any trading decision. 
markedly reduce operating costs; Domowitz and Steil (2001a) show such reductions have typically been $50-75 \%$.

The cost savings from shifting to electronic systems will differ for different users. A more competitive market reduces the ability of exchanges to cross-subsidise different types of trading activity, meaning that the allocation of costs may shift under electronic trading.

In addition, electronic trading can further lower costs if integrated into straight-through-processing (STP) arrangements, which allow trades to pass automatically through to final settlement without further manual intervention. As well as the savings due to automation and error reduction, costs can be cut by linking the execution, clearing and settlement of trades to the procedures for controlling market and operational risks. According to CGFS (2001a), some institutional investors believe that the prospect of STP could be the greatest single potential benefit of electronic trading.

\subsubsection{Implicit costs}

The bid-ask spread paid by users of dealer markets could be regarded either as a payment to the dealer for providing liquidity or as a rent charged for accessing the market. It must cover dealers' normal costs of doing business (eg order processing, inventory costs, overheads) and a risk premium to compensate for the losses incurred when trading with well informed traders (adverse selection). Electronic trading may reduce all these components. It obviously allows cheaper order processing and lower overheads in general. Moreover, electronic trading's potential to make markets more transparent in conjunction with anonymity reduces the risk premium and may drive down profit margins, by increasing competition between dealers and aiding price comparison. Some auction markets give end investors direct access, which might be regarded as them earning the bid-ask spread by providing liquidity. Profit margins are likely to be particularly low in electronic order books that allow access to end investors.

A number of empirical studies show that realised bid-ask spreads on electronic systems are similar to, or lower than, those on floor- or telephone-based systems. ${ }^{23}$ German bund futures provided a case study when in the mid-1990s they were traded in large volumes under otherwise similar conditions on both the electronic Eurex market in Frankfurt and the LIFFE floor in London. Comparisons by Breedon and Holland (1998) and Frino et al (1998) found that spreads were generally wider on the floor exchange, at least when the two exchanges had similar volumes.

Market impact costs refer to any adverse impact on price as a result of information associated with the trade leaking ahead of execution, or because the trade is large enough to affect significantly supply and demand in the market or signal a predictable trade to come. As discussed above, electronic trading may reduce these market impact costs, for example through the use of the pre-trade nontransparent systems. This is an area where electronic trading is widely held to have great potential with several new systems aiming at adding value. More generally, studies by Vila and Sandman (1995) and Pirrong (1996) find that prices are less sensitive to volumes in automated than traditional markets.

\subsection{Price dynamics}

Effective price discovery is important beyond the immediate asset market, since it underlies the accuracy of price signals to agents in the wider economy. This enables appropriate investment (and other) decisions which have widespread economic impact, contributing to ultimate objectives of broader welfare.

Price formation in electronic trading systems is the outcome of precise order execution algorithms, in contrast to the trading floor or phone-based systems where relationships may matter as much as price

23 See, for example, the articles listed by Domowitz and Steil (2001a). Domowitz (2001) claims "all things equal, average trading costs are lower by 33 to 46 basis points in markets which are largely automated". Jiang et al (2002) show that the introduction of electronic trading in the Hong Kong futures market lowered bid-ask spreads, even after allowing for changes in price volatility and trading volume. 
or size. ${ }^{24}$ Furthermore, electronic trading is allowing basic algorithms to be extended to better meet trading needs and, for example, some now permit very detailed trading plans with contingent orders reflecting the various nuances of preferences. Systems are being developed for "near matches": when bids and offers do not coincide, a computerised negotiating system may try to reach a compromise price.

In general, electronic processing should allow orders to reach the central market faster because of higher processing speeds than with manual processes. Prices should therefore incorporate information more quickly. Domowitz and Steil (2001a) found that most empirical studies show that electronic systems are more efficient in this sense than traditional trading venues. However, in some studies the difference is quite marked while in others it is rather small.

\subsubsection{Effects on price volatility}

Studies comparing observed price volatility in traditional and electronic markets generally find that volatility is less or about the same in electronic markets. The following recent studies give a flavour of the findings. Jiang et al (2002) observe that price volatility dropped in the Hong Kong futures market after the introduction of electronic trading but as a similar drop occurred in the spot market, their results suggest that electronic trading itself had little effect on volatility. Chaboud and Weinberg (2002) report mixed evidence for the foreign exchange market. Using over a century of data from the London Stock Exchange, Green et al (2000) find that, other things being equal, lower transactions costs reduce price volatility. Madhavan (1996) suggests that in large liquid markets price volatility is lower when there is greater transparency. These latter results would imply that more widespread electronic trading should lower price volatility.

Some market participants suggest that price volatility is more "visible" as price transparency has increased in some markets - cited by CGFS (2001a). Systems are technically capable of extremely rapid change (eg EuroMTS can absorb 150 price changes per second) and in some markets the use of pricing engines allows orders to be generated more rapidly than hitherto. The micro design of trading systems may also affect price volatility over very short periods. For example, Soejima (2001) shows how changes to the system of execution in the Japanese futures market had to be amended when it was found that traders had insufficient time to respond to new information on the order book.

\subsubsection{Effects on price discovery}

The effects of the increased opportunities for trades to be executed with little interaction with other orders and/or without reaching a main market are keenly debated. Electronic trading is closely associated with the issue since it enables many systems to perform this order matching but the debate - which is typically voiced with respect to the equity market - goes much broader. ${ }^{25}$

Three factors have a particular influence. The first is where orders become more thinly spread among fragmented venues. The second is increasing internalisation, where brokers match buy and sell orders internally from their own customers at prices (broadly) determined on another market, sending only the net balance to the exchange. The third is the number of formal, non-exchange "crossing" systems for institutional trades that are now also part of the market, which match at the prevailing main exchange price.$^{26}$ There seems to be no clear conclusion about the combined effect of these on price formation,

24 In electronic systems, price is usually the first criterion, priority being accorded to the highest bids and lowest offers. The most common secondary criterion is time, with orders transacting on a "first come, first served" basis. Other systems spread a new matching bid pro rata over all the offers at that price. In some systems, market orders may be given priority over limit orders, large orders over small orders, openly disclosed orders over anonymous orders, or those from designated market makers over those of other traders. Another possibility would be for a system to trade off automatically price versus credit risk in accepting bids. Domowitz (1993) provides a taxonomy of these algorithms and describes those used by systems in the early 1990s.

25 For examples of market comments about electronic trading possibly degrading the quality of prices, see Morris (2001) and McNee (2000).

26 There are other instances - not necessarily associated with electronic trading - where prices in one market are largely determined by prices in another, possibly more liquid, market. Examples include off-the-run bonds, whose price movements largely reflect those of on-the-run bonds. In Japan, yields in the government bond market are largely driven by developments in the more liquid futures market. Between the polar cases of pure price making and price taking there are also systems that set the price within limits of prices from a central market. 
despite their increasing importance in markets. However, the following comments give a flavour of the arguments.

One issue is how crossing or internalisation effectively "free rides" on central price discovery and hence the extent to which price information is a public good. For example, Lin, Geng and Whinston (in this volume) describe crossing as a "parasite of real exchanges" while Picot et al (1995) argue it impinges on the "property rights on the price discovery" of an exchange. There are also regulatory concerns including whether internalised transactions are conducted at a "fair" price and whether crossing systems encourage attempts to manipulate the main market just ahead of the price taking for the crossing trades. Transparency can also be reduced by internalisation or crossing, though this depends on the trade publication rules prevailing in any centre.

However, significant cost savings are available ${ }^{27}$ from crossing and internalisation - although the extent to which customers benefit from this can vary. Additionally specialist crossing systems are used by institutions to avoid information leakage. Both these may have some bearing on pricing.

Another aspect of the question is whether there is a "genuine" problem regarding pricing. Other markets (for example, many commodity markets) operate on the basis of the "central" market reflecting more the net balance of buy and sell orders rather than gross volumes. The resultant price should be the same, as all the supplies and demands are still contributing to price formation. It could be argued that this form of price determination is more cost-effective and hence generally beneficial to broader welfare provided the regulatory safeguards operate satisfactorily, such as ensuring customers have the means to access a fair price.

The policy questions closely relate to those surrounding the problems of fragmented markets and of transparency. Problems might be expected to be self-corrected if arbitrage processes, especially in combination with more effective information systems and market linkages, lead to the natural migration of business to platforms where there is confidence in the price formation and integrity of the market. On the other hand, there is scope for self-correction to be limited by rigidities (such as the dominance of some cartel or private incentives of intermediaries) while it may also be held damaging to allow even "temporary" problems to continue (eg the practical problems of thin, illiquid markets).

\subsection{Liquidity}

Liquidity is essential for trading systems. It enhances the effectiveness of the market overall, reducing costs by narrowing spreads and giving depth such that prices are less affected by particular trades. Liquid markets are typically better placed to absorb shocks than less liquid ones, contributing to the robustness of financial systems. Moreover, as discussed in the previous section, liquidity is an essential ingredient of price discovery and hence price signals for the wider economy. ${ }^{28}$

Despite the technological and strategic efforts of electronic trading systems to attract liquidity (see below), it is generally those with existing access to order flow (particularly within an existing exchange) that have experienced viable volumes. Few "standalone" systems have achieved this. This, however, probably reflects the powerful network effects of liquidity as much as the characteristics of the electronic systems themselves - with liquidity attracting (and "locking in") liquidity. There are converse hurdles to attracting business to new venues in the absence of many other users, even if a technically "better product" is on offer (see Box B). ${ }^{29}$

Nevertheless, in a world of electronic trading, liquidity is much more mobile. Orders can be rerouted to the preferred system and to the best prices, and franchises can be quickly lost. This "tipping effect" was seen when Eurex within around six months in early 1998 took all the volume in the futures on the 10 -year German bund contract from the previously dominant LIFFE floor.

27 Conrad et al's (2001) study of the US equity market finds that for crossing networks average implicit cost is $0.23 \%$ and explicit cost $0.07 \%$ compared with $0.54 \%$ and $0.27 \%$ respectively for full service brokers.

28 Characteristics of liquidity in markets are discussed in the policy context in BIS (2001) and from a theoretical perspective in O'Hara (1995). There is discussion of the impact of the internet on equity market liquidity in Madhavan (2000a). Some evidence on electronic trading and market resilience is discussed in CGFS (2001a,b).

29 Analogies can be made with other areas of e-finance, such as the difficulties and/or high costs of internet-only banks attracting funds (see the paper by de Young in this volume). 


\subsubsection{Electronic trading systems' ability to build liquidity}

Focusing on the level of the trading system design, ${ }^{30}$ electronic systems are developing a number of ways to attract liquidity and seek it out from disparate sources. For example, systems can link to institutions' order management systems to interrogate potential orders on their blotters of prospective trades to seek out possible crossing matches. In due course, traders may be able to use "smart agents" to search across systems to locate disparate sources of liquidity.

Electronic trading systems may encourage issuers to standardise their offerings (which can concentrate liquidity), particularly in more heterogeneous securities such as fixed income. There has been some suggestion of this in government bond markets with the tendency to reduce the number of separate issues. Minimum size limits on issues to be eligible for certain trading systems similarly encourage issues to be made in larger size or reopened to maximise liquidity.

Though electronic trading has typically come later to less liquid assets (as illustrated in Section 2), routes are being developed to enable their cost-effective trading. Here, the most effective automation solutions may not be those which reproduce traditional procedures. For example, in fixed income markets, there is an expectation that small, less liquid issues could get swept up into automated trading of portfolios which offer certain characteristics, rather than being traded bilaterally on their own merits. This kind of development offers the potential to garner individually disparate, illiquid securities and pull them into a larger liquidity pool - for example, see the discussion in Fan et al (2000).

Another way in which electronic systems are enabling the more effective trading of illiquid securities is by reviving the use of periodic call auctions (explored in Schwartz et al (2001)). A number of stock markets now trade less liquid securities in call auctions, commonly one to three times a day, concentrating liquidity that otherwise would have been thinly dispersed across a longer period. Such securities may not trade effectively in the continuous auctions that typically form main markets - for example, Steil (2001) describes how the Warsaw Stock Exchange, re-established in 1991, initially traded stocks in a weekly call, moving to daily calls and later (for some stocks) to continuous trading as volumes grew to give sufficient liquidity.

\section{Concluding remarks: wider implications and policy}

This final section does two things. First, it draws together some wider implications of the effects of electronic trading in three areas: the regulatory framework/oversight issues; networks and competition; and financial stability. Second, in each of these areas it draws some tentative policy conclusions. As already set out, there are multiple, possibly competing, public policy objectives along with uncertainties about the net effect of changes in markets and their transmission to broader welfare. The recognition of these uncertainties and ambiguities in itself deserves considerable weight in policymaking.

\subsection{Regulatory framework and oversight issues for markets}

Developments associated with electronic trading test long-standing institutional structures and appear on regulatory agendas worldwide. ${ }^{31}$ Notable issues include:

- frameworks for regulation: notably whether to (continue to) differentiate the institutional status and oversight regimes applying to exchanges and non-exchange trading systems;

30 Clearly the enhanced possibilities for market access offered by electronic trading themselves can garner liquidity. Electronic trading's other effects on liquidity can come via influence on fragmentation and consolidation and, connected to this, its influence in allowing trades to be executed away from main markets, for example by internalisation of order flow. Lower trading costs in themselves also attract more trading.

31 For example, US SEC (1998); proposals by the Canadian Securities Administrators (2000) concerning alternative trading systems - discussed in Boisvert and Gaa (2001); discussions in the United Kingdom - see Financial Services Authority (2000) and Wisbey (2000). This section highlights some key, underlying issues. Details about the debates and the complexity of considerations can be found in the documents referenced. 
the appropriate level of detail for official involvement in microstructure matters - for example, whether transparency rules are required or can be enforced, and in what degree of detail; or whether fragmentation of markets requires an active response; and

cross-border issues raised by remote access to trading, including whether countries' different regulatory regimes lead to problems caused by regulatory arbitrage; and clarification of jurisdiction over legal and regulatory arrangements.

It is worth reiterating that in immature, fast-changing markets, some perceived problems may be temporary effects perhaps associated with early stages of product cycles, whereas others may reflect sustained suboptimal positions. The questions associated with fragmentation illustrate this. Policy treads a difficult line between imposing requirements that restrict innovations, while maintaining market integrity and confidence in periods of rapid change. Even if aspects of markets are perceived as functioning suboptimally, it is recognised that specific intervention can be counterproductive. Greenspan (2000) captured the concerns, stating that the authorities "would do well to heed the advice offered to the medical profession and, first, do no harm". Since market structures that had given rise to concerns may change rapidly, the presumption may be that specific intervention is inadvisable unless there is demonstrably a sustained problem.

Where action is deemed preferable (say, where correcting market forces are believed to be weak), there will also be differing regulatory stances about solutions. These could range from ensuring facilitating frameworks such as clear legal codes, action on competition policy such as removing restrictive practices, to specific micro-rule-making on, say, trading protocols. When weighing choices, the differences between and within markets are important - as already evidenced by the varied adoption of electronic trading and the variety of services becoming available. Added to this is recognition of the imprecise understanding of the net effects of changes in market structures/rules such as the mixed impact of transparency rules. All this supports the avoidance of a "one size fits all" approach and argues in favour of being wary of imposing detailed, cross-market rules at a high level.

Electronic trading systems still have further to go in capturing the subtleties of trading - and a similar comment applies to market structure research and its application to policymaking. However, while technology's effects raise many difficult issues in markets, technology can also contribute to solutions:

- It can be applied to enable more efficient and effective collation of data on market performance and behaviours - helping both oversight and understanding of markets. For example, the fulfilment of market-maker obligations could be monitored automatically, or erratic market movements, whether due to trader errors or more fundamental reasons, could be identified rapidly.

- It may directly offer solutions to problems, such as the means to build information systems or link fragmented pools of liquidity.

- It can help participants make better informed decisions, for example by enabling more appropriate transparency arrangements, providing greater information about order routing and features of the assets.

\subsection{Networks and competition}

The raised profile of "physical" (or indeed "virtual") network issues in trading comes in addition to the better known, powerful network economics effects. Some associated policy issues, such as fairness of network access, may be akin to those faced by regulators of other industries such as telecoms where the networks have been opened to competition. From the interest of financial authorities, there are also parallels with oversight of payment systems, in which, quoting from Bank of England (2000), "as with other significant components of the economic infrastructure, there is a public policy interest in ensuring that a competitive environment exists and that any competitive abuses are curbed".

As highlighted in Box B, the competitive landscape can shift rapidly. For example, outcomes of competing but interoperable systems are likely to become more common in securities trading (as seen in, for example, telephone networks). This occurs as network interoperability and linkages between systems contribute to the lessening of physical hurdles to entering markets, for example removing the disadvantage of requiring separate screens for alternative systems. Moreover, while it is never easy to compete successfully with a dominant system, the effects of electronic markets open up more possibilities for tipping to occur, a prospect reinforced by the lower cost base of electronic networks. 
Overall, while electronic linkages might in principle open up markets to competition and enable more "level playing fields", it is not the technology but its implementation that determines the fairness of arrangements. As described by Bar (2001), architectural biases can exist in electronic network markets at least as strongly as, and possibly less visibly than, in traditional structures. Networks can be designed with strategic advantage to certain players, and anticompetitive practices (which restrict the scope for self-correction) may be hard to recognise if they are embedded in the system protocols themselves. ${ }^{32}$ However, electronic network architecture should in principle be more adaptable than traditional market structures, implying that, where identified, problems may be easier and speedier to address.

\subsection{Financial system stability}

Many financial stability issues closely associated with electronic trading are common to discussions of technological innovation and e-finance more generally. The magnitude of uncertainties in conjunction with potential for rapid, wide-ranging change in themselves motivate interest in the whole area. ${ }^{33}$

The concerns typically are due to shifts in emphases rather than completely new risks. For example, the impact of operational problems can be greater in a technologically dependent market. Moreover, and as discussed in Turner (2001), potential systemic implications can arise from the involvement of new and different firms in financial markets, making it more difficult to monitor the linkages and assess the risks to which sectors may be exposed. Especially, the increased importance of non-financial firms, such as telecoms and IT companies, in processes could make channels through which systemic threats arise harder to identify and anticipate.

Many recognised effects of electronic trading - which include opportunities to harness efficiency gains, better market information, handle higher volumes and lessen physical constraints on trading practices and participation - have a role in contributing to the adaptability and stability of the financial system. And while, as with the expansion of any new market, the route will doubtless end up littered with underperforming and failed systems - this in itself does not necessarily carry systemic threats. Indeed, if this brings about greater strength in the remaining platforms, it should contribute to financial stability.

The ambiguity of effects on market performance remains striking. Most observations highly relevant to policy remain in some way equivocal. For example, liquid markets are more resilient than illiquid ones; yet electronic trading is credited with both fragmenting liquidity and enabling it to be brought together from disparate sources. Nevertheless, the potentially volatile nature of liquidity and markets in general, combined with the speed and unpredictability of technical developments, remain in themselves reasons for vigilance.

While electronic trading has brought a range of policy issues to the fore, the associated technological advances may offer routes to solutions. This paper has not attempted to predict outcomes. But it seems likely that the direction of resolution of many of the current questions may lie with the technology itself. And likely too that, as with the assimilation of previous technologies, "electronic trading" will before long cease to be considered as a distinct issue.

32 Three main categories of network bias are described by Bar (2001), as follows. Information asymmetries are where the market is structured so some players have better/earlier market-relevant information. Matching asymmetries are where market clearing algorithms are programmed to favour some participants. Access asymmetries are where different players have differential access to the telecommunications infrastructure.

33 Several official speeches elaborate on these points, for example Crockett (2001) and Greenspan (2000). 


\section{References}

Bank for International Settlements (2001): Market Liquidity: Proceedings of a Workshop held at the BIS, BIS Papers 2, April (www.bis.org).

Bank of England (2000): Oversight of Payment Systems, November (www.bankofengland.co.uk).

Bank of Japan (2001): "Increasing use of electronic trading systems and its implications on Japanese financial markets", Market Review, 2001-E-2, July, Financial Markets Department, Bank of Japan. Originally published in Japanese as 2001-J-1 in January 2001 (www.boj.or.jp).

Banks, E (2001): E-Finance - the Electronic Revolution, John Wiley.

Bar, F (2001): "The construction of marketplace architecture", in Tracking a Transformation: Ecommerce and the Terms of Competition in Industries, Brookings Institution, Washington DC, forthcoming (http://www.stanford.edu/ fbar/Drafts/index.html).

Boisvert, S and C Gaa (2001): "Innovation and competition in Canadian equity markets", Bank of Canada Review, Summer, pp 15-30 (www.bankofcanada.ca).

Bond Market Association (2000): eCommerce in the Fixed Income Markets: the 2000 Review of Electronic Transaction Systems, November (www.bondmarkets.com).

Breedon, F and A Holland (1998): "Electronic versus open outcry markets: the case of the bund futures contract", Bank of England working paper, no 76, February (www.bankofengland.co.uk).

Brown, J (2001): “The inevitability of consolidation”, Euromoney, March, pp 112-8.

Canadian Securities Administrators (2000): "Alternative trading system proposal", OSC Bulletin no 23, July.

Carlton, D and J Perloff (1999): Modern Industrial Organisation, Longman.

Cavaglia, S, C Brightman and M Aked (2000): "The increasing importance of industry factors", Financial Analysts Journal, vol 56, no 5, September/October, pp 41-54.

Chaboud, A and S Weinberg (2002): "Foreign exchange markets in the 1990s: intraday market volatility and the growth of electronic trading" in Market Functioning and Central Bank Policy, BIS Papers, forthcoming.

Claessens, S, T Glaessner and D Klingebiel (2000): "Electronic finance: reshaping financial landscapes around the world", Financial Sector Discussion Paper, no 4, World Bank, September (www.worldbank.org).

(2001): "E-finance in emerging markets: is leapfrogging possible?", Financial Sector Discussion Paper, no 7, World Bank, June (www.worldbank.org).

Committee on the Global Financial System (2001a): The Implications of Electronic Trading in Financial Markets, Bank for International Settlements, Basel, January (www.bis.org ).

(2001b): "Structural aspects of market liquidity from a financial stability perspective", Basel, June (www.bis.org).

Conrad, J, K Johnson and S Wahil (2001): "Institutional trading and soft dollars", Journal of Finance, vol LVI, no 1, February, pp 397-416.

Crockett, A (2001): "Market discipline and financial stability", speech at the Banks and Systemic Risk Conference, Bank of England, London, 23-25 May (www.bis.org).

Davis, E and B Steil (2001): Institutional Investors, MIT Press, London.

D'Avolio, G, E Gildor and A Shleifer (2001): "Technology, information production and market efficiency", presented to the symposium on 'Economic Policy for the Information Economy', sponsored by the Federal Reserve Bank of Kansas City, Jackson Hole, 30 August - 1 September (www.kc.frb.org./Publicat/sympos/2001).

Debt Management Office (2000), The Secondary Market for Gilts: a Consultation Paper, January (www.dmo.gov.uk).

Domowitz, I (1993): "A taxonomy of automated trade execution systems", Journal of International Money and Finance, vol 12, no 6, December, pp 607-31. 
(2001): "Liquidity, transactions costs and reintermediation in electronic markets", paper presented to Financial E-commerce Conference of the Federal Reserve Bank of New York, April (www.smeal.psu.edu/faculty/ihd1/Domowitz.html).

Domowitz, I, J Glen and A Madhavan (2000): "Liquidity, volatility and equity trading costs across countries and over time" (www.smeal.psu.edu/faculty/ihd1/intcost1.pdf).

Domowitz, I and B Steil (2001a): "Automation, trading costs, and the structure of the securities trading industry", Chapter 7 of Davis and Steil (2001). (An earlier version appeared in R Litan and A Santomero (eds), Brooking-Wharton Papers on Financial Service, 1999, pp 33-81).

(2001b): "Innovation in equity trading systems: the impact on transactions costs and cost of capital", in R Nelson, D Victor and B Steil (eds), Technological Innovation and Economic Performance, Princeton University Press (www.smeal.psu.edu/faculty/ihd1/innovation1.pdf).

Economides, N (1996): "The economics of networks", International Journal of Industrial Organisation, vol 16, no 4, pp 673-99 (raven.stern.nyu.edu).

(2001): "The impact of the internet on financial markets", Journal of Financial Transformation, vol 1, no 1 (www.stern.nyu.edu).

Economist, The (2000): "E-bonds, licensed to kill", 15 January.

(2001a): "Rise and fall: a survey of global equity markets", 5 May.

(2001b): "The hunt for liquidity", 28 July.

Fan, M, J Stallaert and A Whinston (2000) "Designing electronic market institutions for bond trading", in E Melnick et al (eds) Creating Value in Financial Services, Klewer Academic Publishers, Boston.

Ferguson, R (2001): "Remarks" on D'Avolio, Gildor and Shleifer (2001), August (www.kc.frb.org./Publicat/sympos/2001).

Financial Services Authority (2000): "The regulation of market infrastructure", January (www.fsa.gov.uk).

Frino, A, T Mclnish and M Toner (1998): "The liquidity of automated exchanges: new evidence from German bund futures", Journal of International Financial Markets, Institutions and Money, vol 8, no 3, December, pp 225-41.

Gaa, C, R Ogrodnick, P Thurlow and S Lumpkin (2001): "Future prospects for national financial markets and trading centres", Financial Market Trends, OECD, no 78, March.

Ganley, J, A Holland, V Saporta and A Vila (1998): "Transparency and the design of securities markets", Financial Stability Review, Bank of England, vol 4, pp 8-17.

Goodhart, C and M O'Hara (1997): "High frequency data in financial markets: issues and applications", Journal of Empirical Finance, vol 4, no 2, June, pp 73-114.

Gravelle T (2001): "Market microstructure of dealership equity and governments securities markets", paper presented to Bank of Canada conference on Financial Market Structure and Dynamics, Ottawa, November.

Green, C, P Maggioni and V Murinde (2000): "Regulatory lessons for emerging stock markets from a century of evidence on transactions costs and share price volatility in the London Stock Exchange", Journal of Banking and Finance, vol 24, no 4, April, pp 577-602.

Greenspan, A (2000): "Electronic finance" remarks to the 9th Annual Financial Markets Conference of the Federal Reserve Bank of Atlanta, October (www.federalreserve.gov).

Group of Ten (2001): Report on Consolidation in the Financial Sector, Basel, January (www.bis.org).

Hawkins, J and D Mihaljek (2001): "The banking industry in the emerging market economies: competition, consolidation and systemic stability: an overview", BIS Papers 4, September (www.bis.org).

Jiang, G, N Tang and E Law (2002): "Electronic trading in Hong Kong and its impact on market functioning", in Market Functioning and Central Bank Policy, BIS Papers, forthcoming. 
Leahy, M, S Schich, G Wehinger, F Pelgrin and T Thorgeirsson (2001): "Contributions of financial systems to growth in OECD countries", Economics Department Working Paper no 280, OECD (www.oecd.org).

Lee, R (1998): What is an Exchange?, Oxford University Press.

Levine, R (1997): "Financial development and economic growth: views and agenda", Journal of Economic Literature, vol 35, pp 688-726.

Long, S (2000): "Online finance: the virtual threat", The Economist, 20 May.

Lyons, R (1998): "Introduction to the international market microstructure issue", Journal of International Financial Markets, Institutions and Money, vol 8, no 3, December, pp 219-23.

Madhavan, A (1996): "Security prices and market transparency", Journal of Financial Intermediation, vol 5, pp 255-83.

(2000a): "In search of liquidity in the internet era", presented to the 9th Annual Financial Markets Conference of the Federal Reserve Bank of Atlanta, October (www.frbatlanta.org).

(2000b): "Market microstructure: a survey", Journal of Financial Markets, no 3, pp 205-58.

McAndrews, J and C Stefanadis (2000): "The emergence of electronic communications networks in the US equity markets", Current Issues in Economics and Finance, Federal Reserve Bank of New York, vol 6, no 12, pp 1-6.

McNee, A (2000): "Looking for a central system", Risk, February, pp 55-6.

Mishkin F and P Strahan (1999): "What will technology do to financial structure?", in BrookingsWharton Papers on Financial Services, R Litan and A Santomero (eds), Brookings Institution Press, Washington DC.

Morris, J (2001): "Forex transformed by mergers", Euromoney, May, pp 61-8.

Moszkowski, G, B Bedell, M Vetto and C Clark (2001): "Trading up 2.0: the new world of electronic trading", Salomon Smith Barney, New York, 22 March.

O'Hara, M (1995): Market Microstructure Theory, Blackwell, Oxford.

Picot, A, C Bortenlaenger and H Roehrl (1995): "The automation of capital markets" Journal of Computer-Mediated Communication, vol 1, no 3. (www.ascusc.org/jcmc/vol1/issue3/picot.html).

Pirrong, S (1996): "Market liquidity and depth on computerised and open-outcry trading systems: a comparison of DTB and LIFFE bund contracts", Journal of Futures Markets, vol 16, no 3, pp 519-43.

Sato, S, J Hawkins and A Berentsen (2001): "E-finance: recent developments and policy implications", Tracking a Transformation: E-commerce and the Terms of Competition in Industries, Brookings Institution, forthcoming.

Schwartz, R, N Beiner and M Humbach (2001): The Electronic Call Auction: Market Mechanism and Trading: Building a Better Stock Market, Kluwer Academic Publishers.

Shapiro, C and H Varian (1999): Information Rules: A Strategic Guide to the Network Economy, Harvard Business School Press.

Soejima, Y (2001): "Order-matching system and order strategy in JGB futures market", Bank of Japan Financial Markets Working Paper 01-J-1 (in Japanese, summarised in Box E of CGFS (2001a)).

Steil, B (2001): "Borderless trading and developing securities markets", in R Litan, P Masson and M Pomerleano (eds) Open Doors: Foreign Participation in Financial Systems in Developing Countries, Brookings Institution.

Study Group on Fixed Income Markets (2001): "The changing shape of fixed income markets", BIS working paper, no 104, September, (www.bis.org).

Tsang, R (1999): "Open outcry and electronic trading in futures markets", Bank of Canada Review, Spring, pp 20-33 (www.bankofcanada.ca).

Turner, P (2001): "E-finance and financial stability", in R Litan, P Masson and M Pomerleano (eds) Open Doors: Foreign Participation in Financial Systems in Developing Countries, Brookings Institution. 
US Securities and Exchange Commission (1998): "Regulation of exchanges and alternative trading systems", Release 34-40760, December. (www.sec.gov).

Vila, A and G Sandman (1995): "Floor trading versus electronic screen trading: an empirical analysis of market liquidity and information transmission in the Nikkei stock index futures market", London School of Economics Financial Markets Group Discussion Paper 218, October.

Wisbey, G (2000): "The challenges of technology - regulation of electronic financial markets", speech to conference on The Challenges Facing Financial Regulation, University of Cambridge, Centre for Corporate and Commercial Law, 6-7 July (www.fsa.gov.uk). 